Paper ID \#18899

\title{
Impact of Instructor Gender on Student Performance and Attitudes in a Chemistry Course for Freshman Engineers
}

\section{Ms. Emma Kaeli, Northeastern University}

Emma Kaeli is a fourth-year undergraduate student at Northeastern University, majoring in chemical engineering and pursuing minors in mathematics and materials science and engineering. Outside of class, Kaeli works as a chemistry tutor and participates in undergraduate research in a materials science laboratory on campus. She also has held co-op positions with Rogers Corporation's Innovation Center and the National Renewable Energy Laboratory.

\section{Mr. Tyler Byrne Cole, Northeastern University}

Tyler Cole is a fourth year undergraduate student completing a B.S. in Chemical Engineering and a M.S. in engineering management at Northeastern University. He has been involved in the Connections Chemistry Review program and first year engineering tutoring for two years. Tyler has held a co-op positions at Genzyme and Amgen.

\section{Mr. Bradley Joseph Priem, Northeastern University}

Bradley Priem is a second year undergraduate student at Northeastern University, majoring in chemical engineering and minoring in biochemical engineering. He has been involved in the Connections Chemistry Review program for one year. He has also held an undergraduate research position in a biomaterials laboratory on campus.

\section{Miss Rachel Lauren Shapiro, Northeastern University}

Rachel Shapiro is a fifth year undergraduate student studying chemical engineering at Northeastern University. She has been involved in the Connections Chemistry Review program for the past 3 years. Rachel works in a chemical engineering lab on campus, has held a co-op position at Davol, Inc., a co-op position at Entrega Biosciences, and ia currently completing her third co-op with McKinsey \& Company.

\section{Dr. Paul DiMilla, Northeastern University}

Paul A. DiMilla is an Associate Teaching Professor in Chemistry \& Chemical Biology and Chemical Engineering at Northeastern University. During his academic career at Carnegie Mellon University, Boston University, and Olin College he has been the recipient of the first Whitaker Young Investigator Award from the BMES, a Searle Scholar Award, and an Early Career Development Award from the NSF as well as a three-time recipient of the Omega Chi Epsilon Outstanding Faculty Award from the Northeastern Student Affiliate of AIChE. He also has led industrial R\&D teams at Organogenesis Inc. and Polymerix Corporation developing tissue-engineered medical products and drug- generating biodegradable polymers, respectively, and has co-founded Automated Cell, Inc. In addition to being an inventor on 11 issued US patents, he has published the textbook General Chemistry for Engineers with Cognella Academic Publishing.

\section{Ms. Rachelle Reisberg, Northeastern University}

Rachelle Reisberg is Assistant Dean for Engineering Enrollment and Retention as well as Director of Women in Engineering at Northeastern University. Prior to joining Northeastern University, Rachelle held a wide range of management positions in IBM, Hanover Insurance, and was the President of a high tech start-up company. 


\title{
Impact of Instructor Gender on Student Performance and Attitudes in a Chemistry Course for Freshman Engineers
}

\begin{abstract}
This study analyzes correlations between the gender of engineering students and their instructors and student perceptions, interactions, and successes in a general chemistry course for freshman engineers. Previous studies have shown that female engineering students are, in general, more comfortable seeking help than their male counterparts. Female students are also more likely to seek supplemental instruction (SI), including attending lecturer and TA office hours and lecturerled reviews. As retention of female students is a critical initiative for undergraduate engineering programs, understanding the motivation of students to utilize, or not utilize, SI resources is important to improving student and program success.
\end{abstract}

The data for this study are based on students enrolled in a required fall-semester general chemistry course for freshman engineers at Northeastern University. Thirteen instructors, consisting of three male and one female lecturers and seven male and two female TAs, served as providers of SI. More than 400 students ( $25 \%$ female) were surveyed after completing this course in Fall 2015 about their attitudes toward their lecturers and TAs, including approachability, competence, intimidation, and trust. This study seeks to understand the basis for these findings and the impact that lecturer and TA gender has on use of SI and subsequent student success.

This study shows that the instructor gender had a statistically significant impact on the reported comfort of a student with and perceived competence of an instructor. Female students reported less comfort with male instructors, while male students reported that they perceived female instructors to have a lower level of competency. Despite these findings, less than $1 \%$ of students reported that the gender of an instructor affected their use of SI. It was found, however, that students, especially female students, more often reported that they found their male instructors to be more intimidating than female instructors. It was also found that students who had reported having an intimidating male instructor were less likely to seek SI. As shown in previous studies, use of SI has had a positive impact on student performance in a course. Therefore it is possible that the gender of a student and their instructor could impact overall student performance.

\section{Introduction and Background}

The study discussed in this paper sought to determine the impacts that the gender of lecturers and teaching assistants (TAs) has on students' use of supplemental instruction (SI) within a required general chemistry course for freshman engineers. Previous studies have shown that students who participate in SI tend to perform better in class, as they have additional clarification and exposure to course material. Based on this finding, this study analyzed whether student and instructor gender have an impact on use of SI, and therefore student performance, in a general chemistry for engineers course. The chemistry course evaluated in this study was offered in different sections, taught by either a male or female lecturer and a male or female graduate TA. This division of students allowed for analysis of statistics for use of SI in correlation with gender data. 
In STEM fields the gender of lecturers and TAs has a significant effect on student performance in the classroom. Previous studies have reported that students tend to perform better in courses taught by lecturers and TAs of their own gender, particularly when the student is female. [1] Additionally, male students tend to rate male lecturers with higher competency levels than female lecturers, even if the objective quality of instruction is the same. One study, in which an online TA assumed either a male or female identity for two separate classes, confirmed that male students rate the competency of the "male" instructor significantly higher than the "female" instructor for the same level and quality of instruction. [2] Particularly in science and engineering disciplines, same-gender lecturers make students more comfortable in class, which can affect the way students perform in that class. [3] As a result of increased comfort levels, students have a tendency to view same-gender lecturers as role models. [1] [4] Conversely, it has been shown that female students are deterred from continuing their studies when they do not have a female lecturer in their introductory college years to act as a role model. Because there are many more male than female lecturers in the STEM fields, male students often have an easier time viewing their male lecturers as positive role models, reinforcing their confidence towards completing their STEM based degree.

The gender of a student also plays a role in how comfortable the student feels when seeking additional help with coursework and assignments. Asking for help is essential in learning subject material in challenging classes in STEM fields. Use of SI has been correlated with improved student course grades. [5] SI allows students the opportunity to meet individually and in groups with lecturers and TAs, possibly improving their relationship with these instructors and benefitting their overall experience in a course. Even though extra help is offered to all students, the gender of a student can affect their willingness to participate in such SI. It has been shown that asking for help has a negative effect on the perceived competence of males but not of females. [6] Additionally, there exists a stereotype that males are more able to understand concepts in math and science than females. Females are expected to not understand these concepts after an initial introduction, which makes seeking extra help less stigmatized for female students. Conversely, males are expected to express a better understanding of this subject matter upon initial introduction, which may deter them from using SI when they could benefit from it. [6]

As with student comfort, the gender of a student also can impact the overall course experience and performance of that student in STEM-related introductory courses. Before beginning college, male and female students are often at the same competency level in math and science. However, once beginning college, female students are 37\% less likely to obtain a STEM degree when compared to their male counterparts. [1] This outcome may be attributed to the fact that STEM fields are populated largely by male faculty and students; unintentionally suggesting that female students are both not expected to and should not be majoring in a STEM degree. [7] This environment allows for male students to feel more comfortable and confident in pursuing a STEM-related major compared to their female counterparts. Furthermore, students tend to work with same-gender peers on group assignments out of class. Because there are significantly fewer female students than male students in STEM majors, female students have less opportunity to work with a variety of their peers and improve their overall course performance. [3]

For STEM students, particularly female students, self-efficacy - defined as a student's belief in his or her own ability to achieve academic success - is one of the greatest predictors of success 
in academic coursework. Female students, in general, rate themselves with lower self-efficacy in engineering coursework, even when they are, in actuality, achieving the same or better grades than their male counterparts. [7] According to previous research, there are a variety of factors that influence student self-efficacy and academic self-confidence, including perceived lecturer distance and intimidation. [8] Greater perceived faculty distance reflects a colder, detached, and more impersonal teaching style, which affects the overall classroom atmosphere and contributes to perceived lecturer intimidation. Gender stereotypes also play a part in self-efficacy, as according to traditional gender roles male students are better at math and science while female students excel in the humanities. Thus, female STEM students rate themselves with a lower selfefficacy than their male counterparts. [9] In a study done with STEM students in an introductory chemistry course, women had lower self-efficacies and a lower interest in obtaining a STEM degree after completing the course than their male counterparts. In this study male students, over the course of the semester, also reported feeling an increase in the support they received in pursuit of their STEM degree, in contrast to female students who did not feel an increase in support. [9] This lack of support may be attributed to the classroom environment created by the lecturer. As self-efficacy and interpersonal connection are key motivators of female student achievement and comfort in the classroom, decreased faculty distance and lessened perceived intimidation are critical to student success. [8] [10]

The population for this study consisted of 431 students enrolled during the Fall 2015 semester in a required first semester general chemistry course for engineers targeted for freshmen. This course was offered in six lecture sections, each taught by a university professor: five sections taught by male lecturers and one by a female lecturer. Lecture sections had between 50-100 students and met three times a week in 65-minute blocks. Each lecture section was divided into subsections with approximately 30 students for recitation taught by a TA. Recitation met once a week for 100 minutes and was a required class during which students could review information taught in lecture, ask questions on the week's on-line homework assignment, and take quizzes. Recitations were taught by seven male and two female TAs during the Fall 2015 semester. Students' course grades were determined by a weighted combination of recitation attendance, weekly recitation quizzes, homework assignments, midterm exams, a final exam, and a group project in which students worked together in teams of three to four students to investigate the role of chemistry in addressing a problem of global and/or societal importance.

Students enrolled in this chemistry course had various forms of SI offered to them each week throughout the semester. One form of SI analyzed in this study was lecturer and TA office hours, consisting of hour-long blocks during which attending students could ask questions about lecture material, homework assignments, exams, or group projects. Another form of SI consisted of lecturer-led review sessions, which were commonly held before exams in order to review material, answer questions, and help students prepare for exams.

\section{Methodology}

All data were taken from (1) an IRB-approved survey administered to students enrolled in General Chemistry for Engineers during the Fall 2015 semester and (2) grade and attendance information provided by lecturers for these students. Most students surveyed had taken some form of high school chemistry; although a small group of students reported no prior coursework 
in chemistry. Grades for students who did not participate in the survey were excluded from this study.

Surveys were administered to students during the last meeting of recitation at the end of the semester by a member of the research team during the first ten minutes of the class. Surveys were administered electronically, with the option for a paper survey in the event the participant did not have a laptop or smartphone. In addition, only students age 18 and older were permitted to take the survey, and all students had the option to "opt out" of the voluntary survey. Each student was asked to enter their unique student I.D. number for the survey so that their responses could be matched with pre-surveys and grades. These surveys were the main source of data for this study and were used to gauge students' feelings towards the course as well as identify the significance of additional factors like gender or past history seeking extra help. Below are the questions analyzed for this study.

What was your comfort level with using the following people as an extra help resource? ( $1=$ least comfortable to $5=$ most comfortable):

_Friend _ Upperclass Student_ _ TA _ Course Instructor _ Other faculty member

Please rank the competence of the following people as a supplemental instructor or tutor? (1=least competent to $5=$ most competent):

_ Friend _ Upperclass Student_ _ TA _ Course Instructor _ Other faculty member

Please check any of the factors that led you to NOT use the following resources.

- Instructor Office Hours:

Gender of Supplemental Instructor/Tutor Intimidating Supplemental Instructor/Tutor

- TA Office Hours:

Gender of Supplemental Instructor/Tutor Intimidating Supplemental Instructor/Tutor

- Instructor-Led Review:

Gender of Supplemental Instructor/Tutor Intimidating Supplemental Instructor/Tutor

Collected data were analyzed for trends, correlations, and significant differences between populations. Two statistical tests, the $z$-test and $t$-test, were used to identify whether populations reported statistically significantly different results. These two tests used the average value for a given population, its standard deviation, and population sizes to determine if a pair of averages were statistically significantly different from one another. A $z$-test was used when the populations in question were both larger than 30; otherwise, a $t$-test was used. Averages examined were either proportions, in which case a proportion $z$-test was performed, or the mean value of the population, in which case a regular $z$ - or $t$-test was performed. These tests produce a $p$-value that was compared against a chosen threshold value of 0.05 for statistical significance. If the $p$-value was lower than this value, the two populations were considered to have statistically different averages or proportions. A one-tailed $z$ - or $t$-test was used in order to determine if one value was significantly higher than another, and a two-tailed $z$ - or $t$-test was applied to determine if the two values were significantly different from one another. These tests were used to analyze the data and establish findings regarding the gender of the student and their instructor and the student's use of SI. [11] 


\section{Results and Discussion}

\section{Population Demographics}

Figure 1 presents the distributions of genders for lecturers, TAs, and students. Surveyed students consisted of 314 (73\%) males and 117 (27\%) females. Four male lecturers and one female lecturer taught the six sections of this course. Most of the enrolled students $(80.05 \%)$ had one of three male lecturers. Similarly, most of the enrolled students $(81 \%)$ had one of the seven male TAs. There was one female instructor and two female TAs. Students were not assigned to individual lecture and recitation sections based on their gender or gender of their instructor or TA. No students had both a female lecturer and female TA.

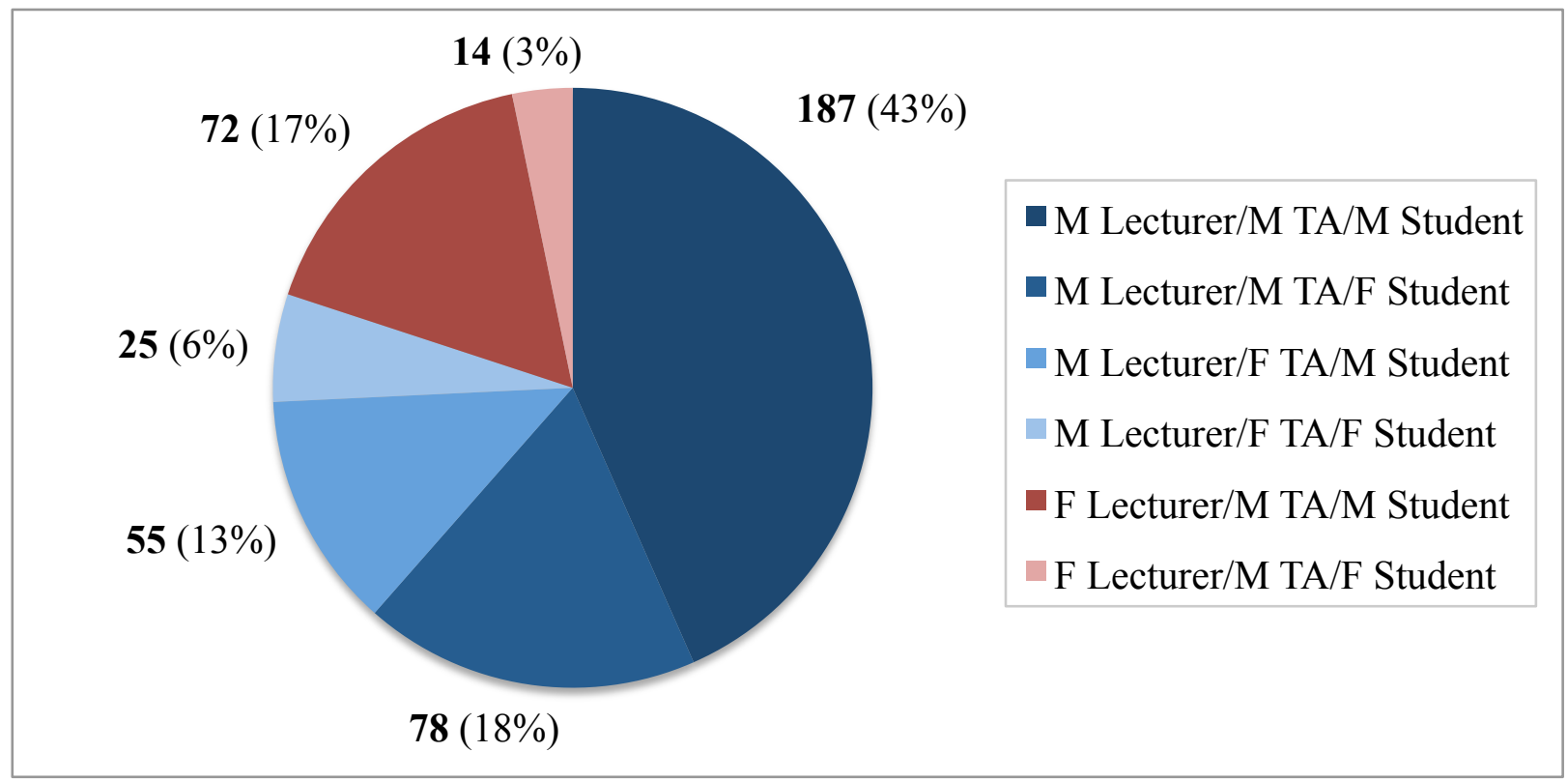

Figure 1. Demographics of students, lecturers, and TAs based on gender.

\section{Gender's Effect on Competence and Comfort}

Student responses concerning the perceived competence of and their comfort with an instructor, whether it be their assigned lecturer or TA, were analyzed for patterns, as presented in Figure 2. Students were divided into populations based on their own gender or that of their instructor. In order to determine whether gender influenced the level of comfort a student felt with an instructor, one-tailed $z$ - and $t$-tests were performed to determine if male or female students felt equally or disproportionately comfortable with male and female lecturers. It was found, with a $p$ value of 0.0068 , that male students felt statistically significantly more comfortable with a male lecturer than females did. Conversely, it was not found that either male or female students felt more or less comfortable with a female lecturer. Although there is an apparent difference in the comfort ratings of male and female students with a female lecturer, based on population size and average ratings, the difference is not large enough to conclude that the two are truly different ratings. This outcome suggests that while the three male lecturers inspired a higher level of 
comfort in male students, the female lecturer did not inspire statistically significant differences in comfort between students with different gender.

Further tests were conducted in order to determine whether gender played a role in the perceived competence of a lecturer or TA, as introduced in Figure 3. Using one-tailed $t$-tests, it was found that both the female lecturer and female TAs were rated as statistically significantly less

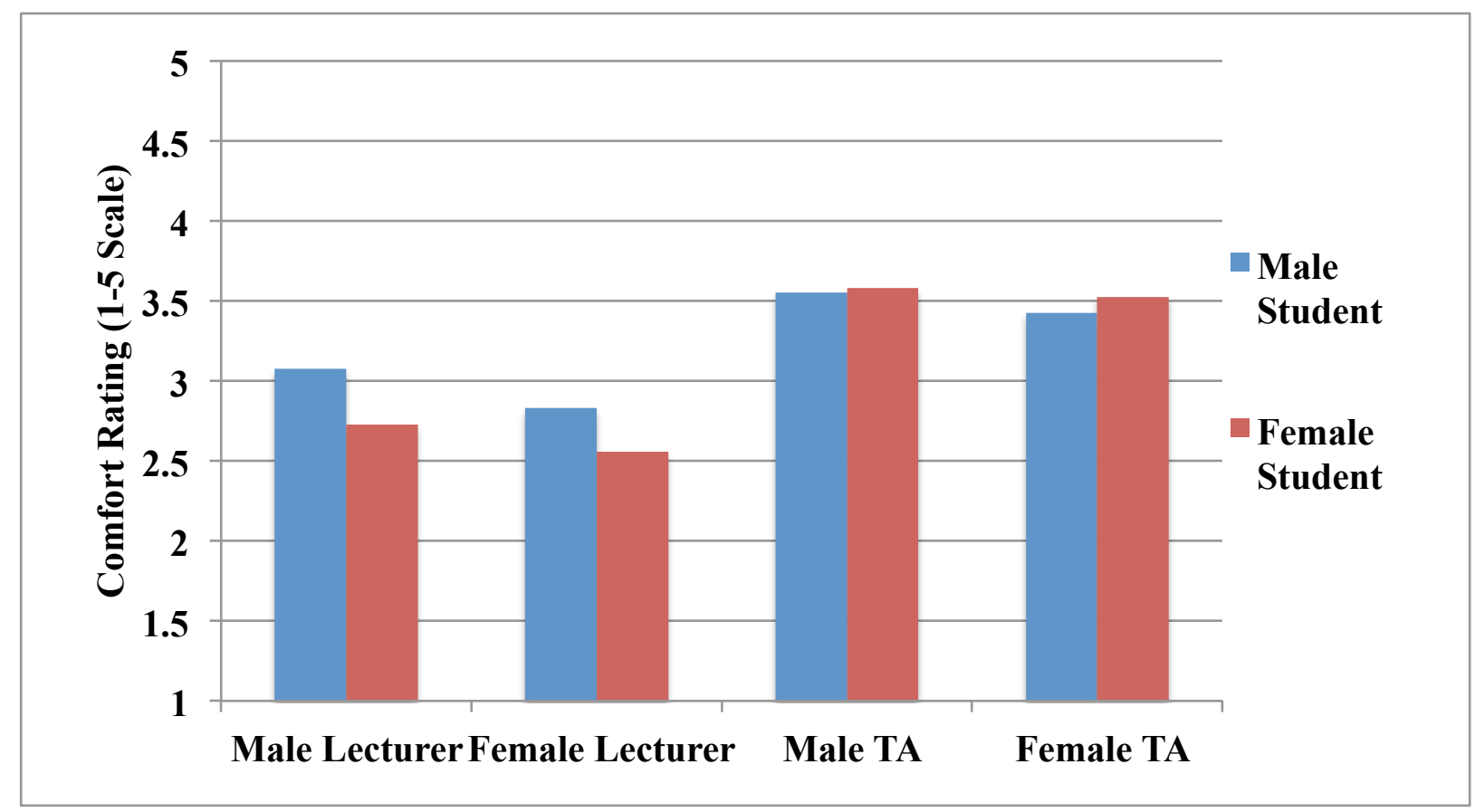

Figure 2. Student ranking of comfort with their instructor

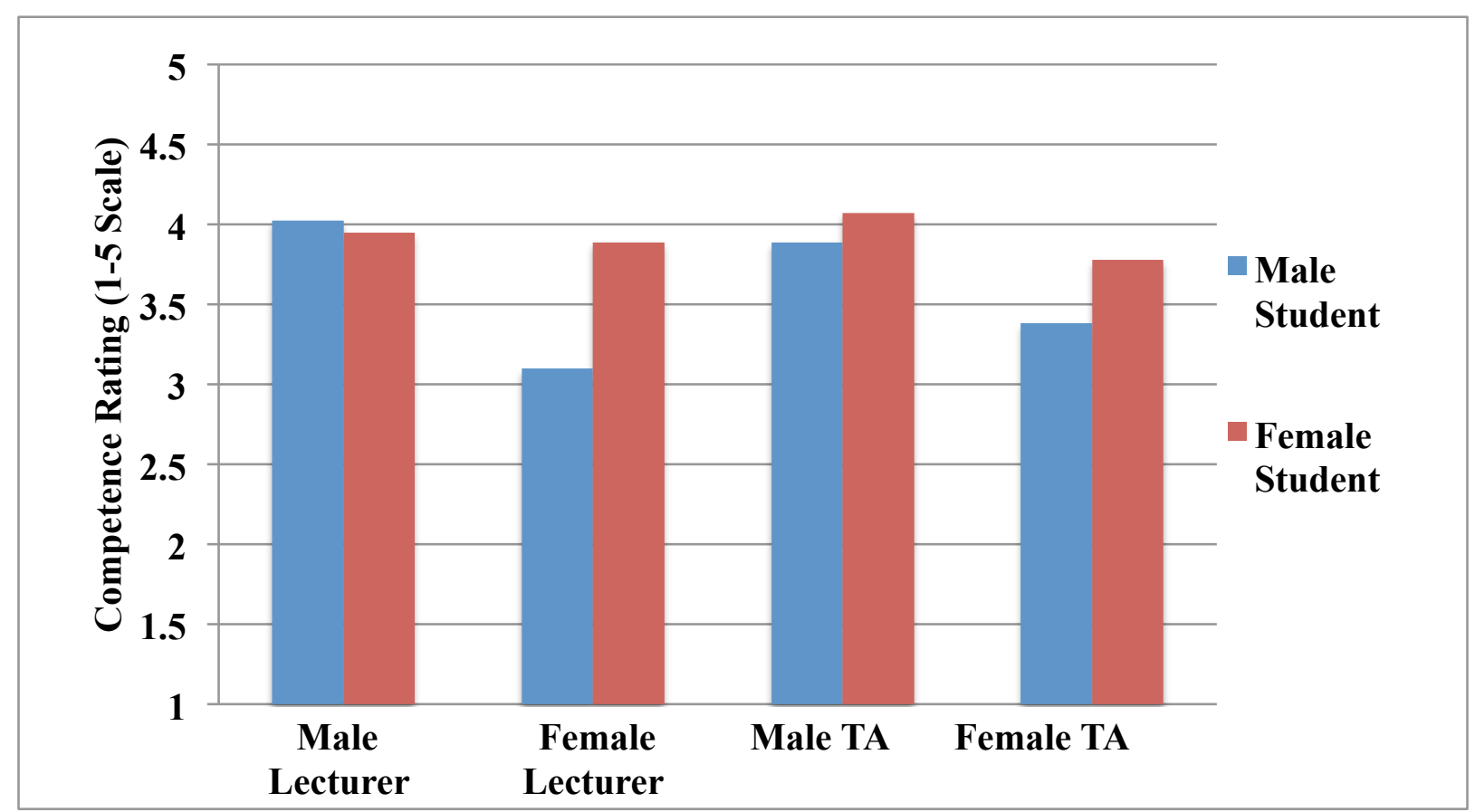

Figure 3. Student ranking of competence for their instructor. 
competent by male students than female students, with $p$-values of 0.03 and 0.05 .

Such a pattern suggests that male students on average find females to be less competent than males when in an instructor role, although further research is needed due to the limited population size of female SI instructors. Not surprisingly, it was found with a one-tailed $z$-test that male students rate male lecturers as statistically significantly more competent than their female lecturer counterparts, with a $p$-value less than 0.001. Among female students, however, such a disparity between the perceived competence of a female $v s$. male lecturer could not be found. The ratings shown in Figure 2 and 3 highlight how the gender of the instructor can affect how male students perceive an instructor. Whether it is a student feeling more at ease or that student's respect for an instructor's intelligence, gender plays an important role that should be further explored.

\section{Student Acknowledgement of Instructor Gender}

Despite the above evidence that instructor and student gender play a role in student perceptions of their learning environment, students may not explicitly recognize the impact of their perceptions. Although information reported by students showed a disparity in student sentiment toward differently gendered instructors, Figure 4 indicates that students were not aware of this effect. In particular, less than $1 \%$ of students report not using a specific type of SI due to the gender of the instructor. Whether it is due to fear of choosing what may be deemed a "sexist" survey response or that students do not correlate evasion of an offering of SI with the instructor's gender, there still exists a disparity in sentiments toward an instructor. This leads to the question: does that disparity in feeling also lead to a disparity in a supplemental instruction resource use?

Gender Affects Use of

Lecturer Office Hours

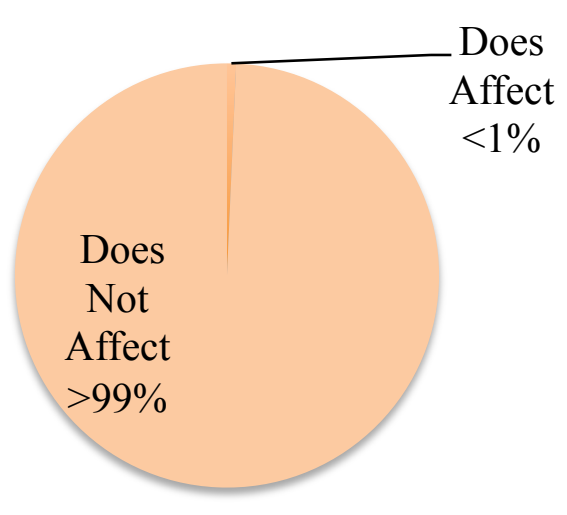

Gender Affects Use of Lecturer Review

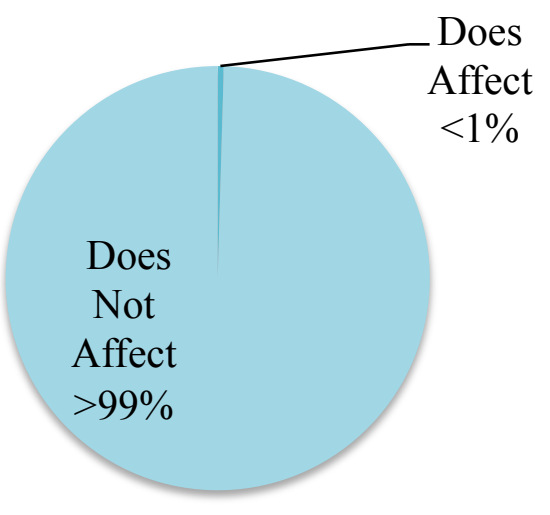

\section{Gender Affects Use of TA Office Hours}

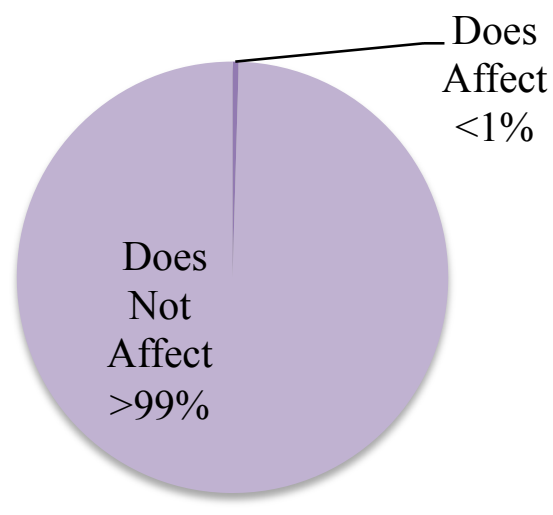

Figure 4. Reported relationships between instructor gender and use of SI.

\section{Gender and Supplemental Instruction Use}

In order to determine if student ignorance of the disparity in feelings toward differently gendered instructors has an effect on use of a resource for SI, the effect of a perceived intimidating 
instructor was analyzed. Figure 5 presents outcomes reported by students regarding whether they chose not to use a type of SI because they found the instructor for that resource intimidating. In order to determine if gender and intimidation can be correlated, a one-tailed two-proportion $z$-test was used. It was found, with a $p$-value of 0.038 , that a statistically significantly higher proportion of students did not use office hours offered by a male instructor than those by the female lecturer reported in the post-survey as due to finding the instructor intimidating. However, this finding bears additional investigation as the low numbers of students that took advantage of any instructor office hours. It is also recommended that a larger sample size of female instructors be used in future investigations to reduce the impact of the individual instructor qualities as opposed to instructor gender.

In order to determine if the gender of the student affected their susceptibility towards intimidation, one-tailed two-proportion $z$-tests were conducted to compare percentages of male and female students reporting not using a form of SI due to an intimidating instructor, as shown in Figure 6. It was found, with $p$-values of 0.0056 and less than 0.001 , that a statistically significantly higher percentage of female students reported not using lecturer reviews and office hours, respectively, than their male counterparts when the lecturer was male. This outcome indicates that the disparity in feelings toward a female and male lecturer had an effect on whether a student used a potentially helpful resource. Furthermore, the same outcome was found, with a $p$-value of 0.003 , in the case of office hours offered by male TAs: female students were more

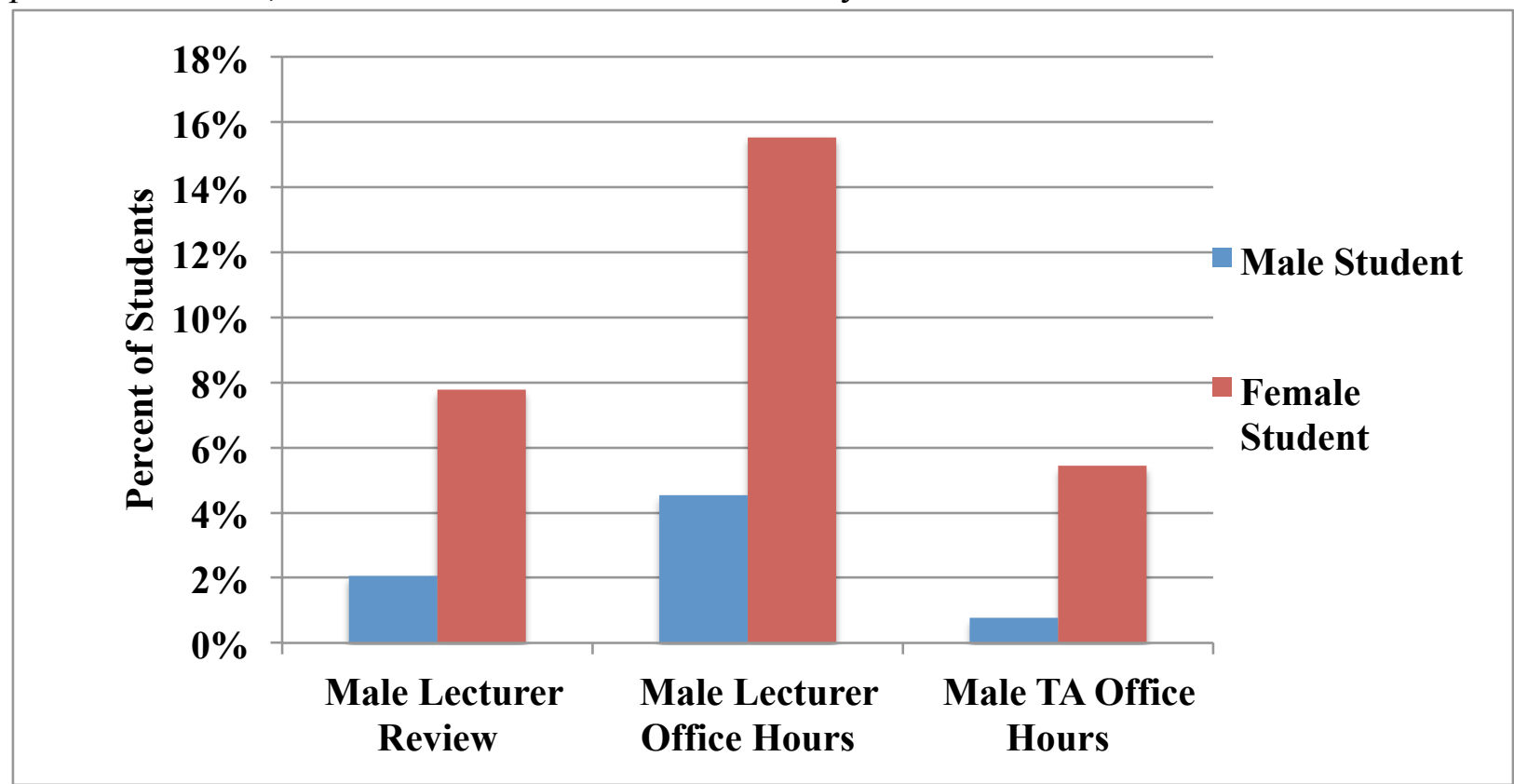

Figure 6. Percent of male and female students who report not using a type of supplemental instruction due to an intimidating male lecturer or TA.

likely than their male counterparts to not use this resource due to intimidation. These points, as shown in Figure 6, indicate that female students may be at a disadvantage when they have a male instructor. Although female and male students did not report statistically significantly different responses regarding use of office hours offered by female lecturers and TAs, the disparity with male instructors could be a handicap for female students. 


\section{Conclusions}

It was hypothesized that gender of a lecturer or TA in a freshmen general chemistry course for engineers affects a student's use of SI. This hypothesis was extended to the belief that the gender of the lecturer or TA subsequently may affect students' performance in class. Two main findings resulted from analysis conducted based on these hypotheses. It was found that the lecturer's gender impacts student comfort level. Specifically, male and female students were equally comfortable with a female lecturer; however, female students were less comfortable with a male lecturer than their male counterparts. Male students described their male instructors as more competent than female instructors; but female students on average described their female lecturers and TAs as more competent than male students. These outcomes indicate that the gender of both the student and instructor impacts how a student perceives their instructor. Despite this finding, less than $1 \%$ of students reported that the gender of the instructor affected their use of SI.

The second set of findings revealed that perceiving an instructor as intimating affected a student's use of SI, regardless of the gender of the student. This effect was especially true for female students. This may imply that the gender of the instructor impacts the use of a resource for SI. Furthermore, it demonstrates that female students may be at a disadvantage compared to their male counterparts when the supplemental instructor is male. In previous studies it was shown that use of SI strongly correlates with performance in a course. These results point to some factors to consider in improving SI usage and, thus, retention, especially of female students. Having more female lecturers and TAs may give females more options to seek out help with an increased comfort level.

From these findings, future studies are recommended in order to understand further the effects of gender on students' use of SI. Increasing the population of female lecturers analyzed, as well as including female TA and lecturer pairs, would provide a more varied sample as this survey period did not include this combination. Additionally, it is recommended that the effects of gender on other forms of SI available to students be examined. This outcome could be made possible by expanding the scope of the research to other freshman engineering courses with more male and female lecturers. Lastly, partnering with counterparts at other universities can provide additional data to support and augment findings presented here.

\section{References}

[1] S. E. Carrell, M. E. Page and J. E. West, "Sex and Science: how professor gender perpetuates the gender gap," The Quarterly Journal of Economics, vol. 125, no. 3, pp. 11011144, 2010.

[2] L. MacNell, A. Driscoll and A. N. Hunt, "What's in a name: exposing gender bias in student ratings of teaching," Innovative Higher Education, vol. 40, no. 4, pp. 291-303, 2015.

[3] B. Artz and D. M. Welsch, "The effect of peer and professor gender on colelge student performance," Southern Economic Association, vol. 80, no. 3, pp. 816-838, 2014.

[4] M. S. Hyde and J. Gess-Newsome, "Adjusting educational practice to increase female persistence in the sciences," Journal of College Student Retention, vol. 1, no. 4, pp. 335 $355,1999$. 
[5] K. B. Coletti, E. O. Wisniewski, R. L. Shapiro, P. A. DiMilla, R. Reisberg and M. Covert, "Correlating Freshmen Engineers' Performance in a General Chemistry Course to their use of supplemental instruction," in American Society of Engineering Education, Indianapolis, 2014.

[6] A. S. Rosette, J. S. Mueller and R. D. Lebel, "Are male leaders penalized for seeking help? The influence of gender and asking behaviors on competence perceptions," The Leadership Quarterly, vol. 26, no. 5, pp. 749-762, 2015.

[7] C. M. Jagacinski, "Women engineering students: competence perceptions and achievement goals in the freshmen engineering course," Sex Roles, vol. 69, no. 11, pp. 64-657, 2013.

[8] C. M. Vogt, "Faculty as a critical juncture in student retention and performance in engineering programs," American Society of Engineering Education, vol. 97, no. 1, pp. 27 36, 2008.

[9] E. E. Hardin and M. O. Longhurst, "Understanding the gender gap: social cognitive changes during and introductory STEM course," Journel of Counseling Psychology, vol. 63, no. 2, pp. 233-239, 2016.

[10] V. J. Morganson, M. P. Jones and D. A. Major, "Understanding women's underrepresentation in science, technology, engineering and mathematics: the role of social coping," Career Development Quarterly, vol. 59, no. 2, pp. 169-179, 2010.

[11] R. J. Larsen and M. L. Marx, An Introduction to Mathematical Statistics and Its Applications, Upper Saddle River, NJ: Pearson Prentice Hall, 2001. 